\section{Hemoperitoneum after endoscopic mucosal resection for Barrett's esophagus}

A 67-year-old man was referred for Barrett's esophagus, Prague classification C8M8, with high grade dysplasia (HGD). A first endoscopic mucosal resection (EMR) using the Duette system (Wilson Cook Medical, USA) allowed removal of half of the circumference of the Barrett's area. The remaining Barrett's zone was resected 1 month later, without peroperative adverse events ( $\bullet$ Fig. 1 ). However, 4 hours after the endoscopy, the patient complained of thoracic and abdominal pain, without subcutaneous emphysema or signs of peritonitis. A computed tomography scan ( $\bullet$ Fig. 2 ) revealed a perisplenic, perihepatic, and pelvic hemoperitoneum; this was associated with an acute fall in hemoglobin $(2 \mathrm{~g} / \mathrm{dL})$ requiring a transfusion. In the event, the patient's course was spontaneously favorable without hemorrhagic shock or recurrence of bleeding. He did not need additional interventions and he recovered fully within 7 days. The pathological analysis confirmed Barrett's esophagus with low grade dysplasia (LGD) and some HGD areas, and with safe resection margins.

As well as focal EMR [1], complete eradication of Barrett's esophagus using EMR techniques is an effective and safe method, with a perforation rate of between $0 \%$ and $9.5 \%$ of cases and a bleeding rate of between $0 \%$ and $2.56 \%$ [2-9]. The major limitation is the incidence of secondary stenosis ( $0 \%$ to $50 \%$ of cases).

To date, this is the first reported case of hemoperitoneum after an EMR procedure. This complication might be have been caused by injury, during submucosal injection or suction, to gastric vessels located in the splenogastric ligament. Hemoperitoneums caused by splenic injury are mainly reported after colonic surgery, when excessive traction of the peritoneal attachments had led to mobilization of the splenic flexure and capsular and hilar bleeding [10-12]. More rarely, colonoscopy can also be complicated with splenic injury [13]. Some authors describe patient-related risk factors of male sex and peripheral vascular disease [10].

In conclusion, hemoperitoneum after EMR is a very rare complication, but awareness of it is needed in order to prevent delayed diagnosis and to provide appropriate care.

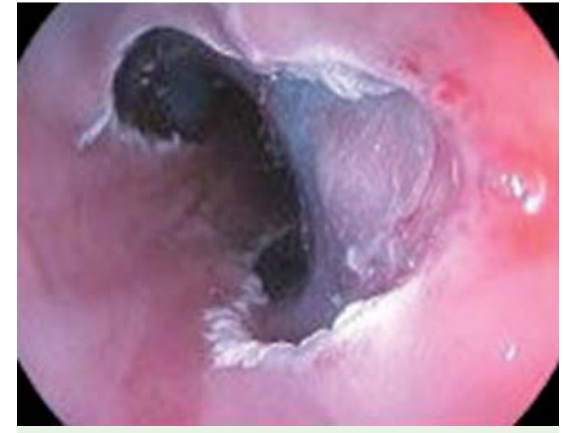

Fig. 1 Endoscopic view of esophageal endoscopic mucosal resection (EMR) for Barrett's esophagus.

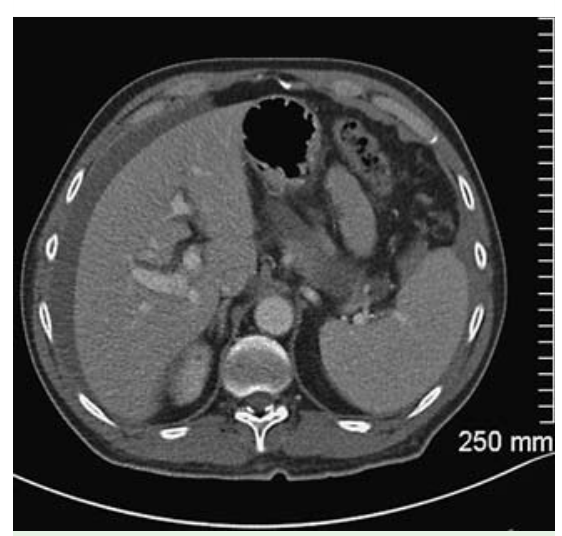

Fig. 2 Computed tomography (CT) scan showing hemoperitoneum.

Endoscopy_UCTN_Code_CPL_1AH_2AZ

Competing interests: None

\section{Pascale Mercky, Jean-Michel Gonzalez, Fabrice Caillol, Erwan Bories, Christian Pesenti, Marc Giovannini}

Endoscopic Unit, Paoli-Calmettes Institute, Marseille, France

\section{References}

1 Ortiz-Fernández-Sordo J, Parra-Blanco A, García-Varona $A$ et al. Endoscopic resection techniques and ablative therapies for Barrett's neoplasia. World J Gastrointest Endosc 2011; 3: $171-182$

2 Seewald S, Akaraviputh T, Seitz $U$ et al. Circumferential EMR and complete removal of Barrett's epithelium: a new approach to management of Barrett's esophagus containing high-grade intraepithelial neoplasia and intramucosal carcinoma. Gastrointest Endosc 2003; 57: 854-859
3 Giovannini M, Bories E, Pesenti C et al. Circumferential endoscopic mucosal resection in Barrett's esophagus with high-grade intraepithelial neoplasia or mucosal cancer. Preliminary results in 21 patients. Endoscopy 2004; 36: $782-787$

4 Peters FP, Kara MA, Rosmolen WD et al. Stepwise radical endoscopic resection is effective for complete removal of Barrett's esophagus with early neoplasia: a prospective study. Am J Gastroenterol 2006; 101: 1449-1457

5 Larghi A, Lightdale CJ, Ross AS et al. Longterm follow-up of complete Barrett's eradication endoscopic mucosal resection (CBEEMR) for the treatment of high grade dysplasia and intramucosal carcinoma. Endoscopy 2007; 39: 1086-1091

6 Lopes CV, Hela M, Pesenti $C$ et al. Circumferential endoscopic resection of Barrett's esophagus with high-grade dysplasia or early adenocarcinoma. Surg Endosc 2007; 21: $820-824$

7 Chennat J, Konda VJ, Ross AS et al. Complete Barrett's eradication endoscopic mucosal resection: an effective treatment modality for high-grade dysplasia and intramucosal carcinoma - an American single-center experience. Am J Gastroenterol 2009; 104: 2684-2692

8 Moss A, Bourke MJ, Hourigan LF et al. Endoscopic resection for Barrett's high-grade dysplasia and early esophageal adenocarcinoma: an essential staging procedure with long-term therapeutic benefit. Am J Gastroenterol 2010; 105: 1276-1283

9 Pouw RE, Seewald S, Gondrie JJ et al. Stepwise radical endoscopic resection for eradication of Barrett's oesophagus with early neoplasia in a cohort of 169 patients. Gut 2010; 59: $1169-1177$

10 Masoomi H, Carmichael JC, Mills S et al. Predictive factors of splenic injury in colorectal surgery. Arch Surg 2012; 147: 324-329

11 Wang JK, Holubar SD, Wolff BG et al. Risk factors for splenic injury during colectomy: a matched case-control study. World J Surg 2011; 35: 1123 - 1129

12 Merchea A, Dozois EJ, Wang JK et al. Anatomic mechanisms for splenic injury during colorectal surgery. Clin Anat 2012; 25: 212 217

13 Lalor PF, Mann BD. Splenic rupture after colonoscopy. JSLS 2007; 11: 151-156

Bibliography

Dol http://dx.doi.org/

10.1055/s-0033-1359161

Endoscopy 2014; 46: E15

(c) Georg Thieme Verlag KG

Stuttgart · New York

ISSN 0013-726X

\section{Corresponding author}

\section{Pascale Mercky, MD}

Hôpital Sainte Musse - Gastroenterology

54, rue Henri Sainte Claire Deville

Toulon 83000

France

Fax: +33-4-94145276

Pascale_mercky@hotmail.com 